\title{
Evaluation of measurement uncertainty of urine output using two kinds of urine bags
}

\author{
Hyo Jung Son', Tae Woong Kim ${ }^{1}$, Han Byeol Oh${ }^{1}$, Yoon Ji Choi ${ }^{2}$ \\ ${ }^{1}$ Department of Anesthesia and Pain Medicine, National Police Hospital, Seoul, ${ }^{2}$ Department of Anesthesia and Pain Medicine, Pusan \\ National University Yangsan Hospital, Yangsan, Korea
}

Received October 30, 2017

Revised November 24, 2017

Accepted December 1, 2017

Corresponding author

Yoon Ji Choi

Department of Anesthesia and Pain

Medicine, Pusan National University

Yangsan Hospital, 20 Geumo-ro,

Mulgeum-eup, Yangsan 50612,

Korea

Tel: +82-55-920-5632

Fax: +82-55-360-2149

E-mail: yoonji07@gmail.com

\begin{abstract}
Measurement of the urine output is helpful in the diagnosis of urinary diseases, including the kidney. However, the various types of urine bags available have many factors that can influence the measurements of the urine output. Therefore, this study examined the measurement uncertainty of the urine output using two types of urine bags. Two types of commonly used urine bags (urine bag with collecting chamber: urine bag $A$, and urine bag only: urine bag B) were evaluated. The volume of the contents in the urine bags was measured after injecting either $30 \mathrm{~mL}$ or $300 \mathrm{~mL}$ of water into the urine bags. The volume of injected water was determined considering the urine bag scale and definition of oliguria, which indicated below $0.5 \mathrm{~mL} / \mathrm{kg} / \mathrm{h}$. When an average of $30.1 \mathrm{~mL}$ of water was injected into urine bag $A$, the measured value was distributed within $\pm 2.4 \mathrm{~mL}(7.0 \%)$ with a $95 \%$ probability. When an average of $30 \mathrm{~mL}$ of water was injected into urine bag $B$, the measured value was distributed within $\pm 6.4 \mathrm{~mL}(21.3 \%)$ with a $95 \%$ probability. When an average of $300 \mathrm{~mL}$ of water was injected into urine bag B, the measured value was distributed within $\pm 58.1 \mathrm{~mL}(19.4 \%)$ with a $95 \%$ probability. This study revealed the measurement uncertainty of the urine output using two types of urine bags. Considering the uncertainty of the measurement, even if the urine volume is within this range, clinically suspected oliguria should be considered and observed closely, and active treatment may be required.
\end{abstract}

Keywords: Uncertainty; Urine bag; Urine output

\section{INTRODUCTION}

A urine bag is a soft bag that collects and stores urine from an instrument inserted into a patient, such as a Foley catheter. The bag is comprised of inlet tubing, outlet tubing, urine drip chamber, urine collecting bag, sample site, and connector. In Korea, the relevant terms, requirements, and test methods are regulated by the international organization for standardization (ISO) [1]. On the other hand, commercially available urine bags have a variety of shapes because the structure and ap- pearance of the urine dripping chamber are discretionary. Therefore, measurements of urine bags have various factors that can influence the volume measurement. This study evaluated the measurement uncertainty of the urine output using two types of urine bags.

\section{MATERIALS AND METHODS}

Two types of commonly used urine bags (urine bag with a collecting chamber, urine bag A; and a urine bag only, urine

This is an Open Access article distributed under the terms of the Creative Commons Attribution Non-Commercial License (http://creativecommons.org/licenses/by-nc/4.0) which permits unrestricted noncommercial use, distribution, and reproduction in any medium, provided the original work is properly cited. Copyright (c) Medical Biological Science and Engineering. 
bag B) were evaluated.

\section{Urine bag $A$}

\section{1) Measurand}

For Koreans, the standard height is $170 \mathrm{~cm}$ to $175 \mathrm{~cm}$ and the body weight is $70 \mathrm{~kg}$ to $75 \mathrm{~kg}$ for men; the height and body weight of women is $158 \mathrm{~cm}$ to $163 \mathrm{~cm}$ and $53 \mathrm{~kg}$ to 58 $\mathrm{kg}$, respectively. Therefore, considering that oliguria is defined as $0.5 \mathrm{~mL} / \mathrm{kg}$, the measurements were determined to be volume of water $(30 \mathrm{~mL})$ injected into urine bag $\mathrm{A}$.

\section{2) Measurement procedure}

A urine bag attached to a precise container commonly used in the department of anesthesiology was purchased and 30 $\mathrm{mL}$ of water was injected. The actual volume, accounting for the measurement uncertainty, was measured (Fig. 1A).

\section{3) Mathematical measurement model}

The volume of water converted from the weight measured directly on an electronic scale using a syringe can be ex-
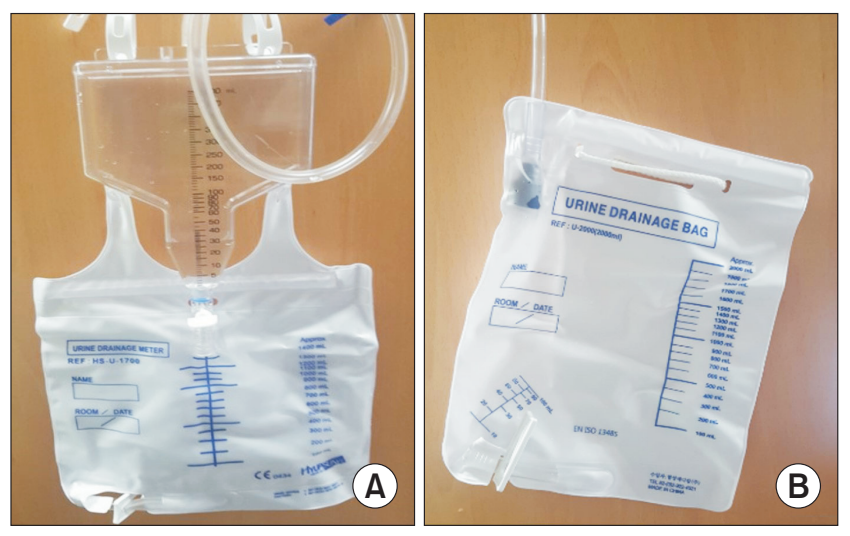

Fig. 1. Urine bag used in this study. (A) Urine bag with a precise container, (B) bag type urine bag. pressed as

$$
A s=f(x)=A b+C .
$$

Here, $\mathrm{Ab}$ is the volume of water measured by the urine bag and $\mathrm{C}$ is the uncertainty corrected for the systematic effect of the urine bag (Fig. 2).

\section{Urine bag B}

\section{1) Measurand}

Urine bag B uses different scale marks. The scales are divided into $10 \mathrm{~mL}$ units up to $100 \mathrm{~mL}$ and into $100 \mathrm{~mL}$ unit at higher volumes. Accordingly, $30 \mathrm{~mL}$ was measured under a $100 \mathrm{~mL}$ volume and $300 \mathrm{~mL}$ was measured in the range exceeding $100 \mathrm{~mL}$.

\section{2) Measurement procedure}

A bag type urine bag commonly used by anesthesiologists was purchased to inject either $30 \mathrm{~mL}$ or $300 \mathrm{~mL}$ of water and measure the actual volume, considering the measurement uncertainty (Fig. 1B).

\section{3) Mathematical measurement model}

The volume of water is converted from the weight measured directly with an electronic scale using a syringe, and can be expressed using Equation 1.

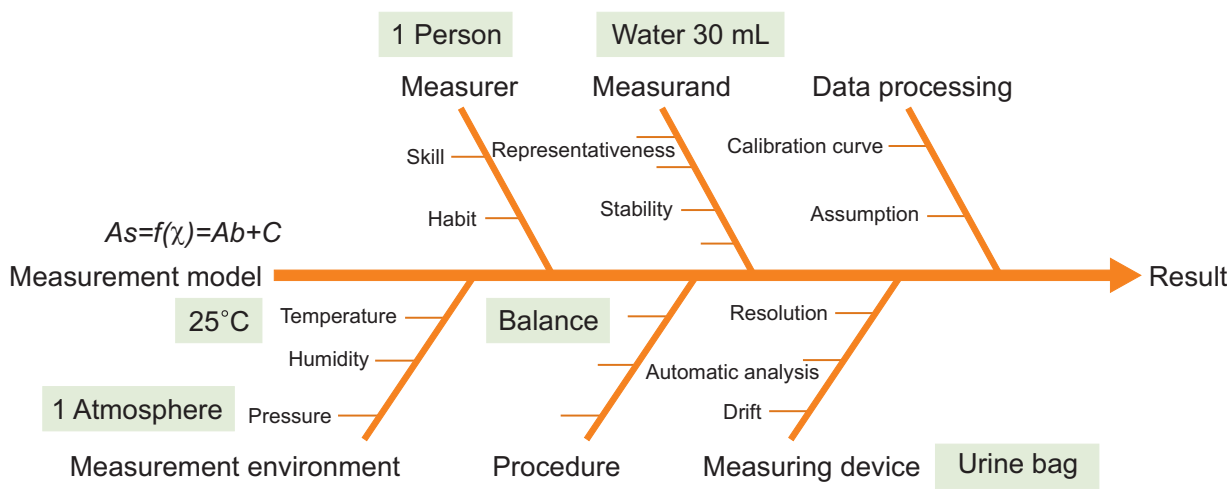

Fig. 2. Measurement of the volume uncertainty of the urine bag. 


\section{RESULTS}

\section{Urine bag $A$}

1) Evaluation of the standard uncertainty of the electronic scale and urine bag

\section{(1) Electronic scale}

The Standard Uncertainty of the electronic scale was obtained from the Calibration Certificate (type A standard uncertainty) [2]. The traceability of the electronic scale (type A) was ensured by repeatedly measuring $30 \mathrm{~g}$ of balance weight on an electronic scale 10 times. The measured value of the 30 $\mathrm{g}$ balance weight was $0.00111 \mathrm{~g}$ higher than the actual value. This was regarded as a systematic error of -0.00111 because it can cause uncorrected errors. The type B standard uncertainty from a resolution of the electronic scale was assumed to follow a rectangular distribution, whose maximum value was $1 / 2$ of the minimum scale [3]. The error of scale of the electronic scale was assumed to follow a rectangular distribution based on the Calibration Certificate.
The normal value for the specific gravity of urine is 1.003 to 1.040 . At $25^{\circ} \mathrm{C}$ and a pressure of 1 atmosphere, $1 \mathrm{~mL}$ of water weighs $1 \mathrm{~g}$. In this case, $30 \mathrm{~mL}$ of urine $=30 \times 1.0215$ (approximate specific gravity of urine) $=30.625 \mathrm{~g}=30.7150 \mathrm{~mL}$ of water, which is a minor difference. For accuracy, this study proceeded with the assumption that injecting $30 \mathrm{~mL}$ of urine is equivalent to injecting $30 \mathrm{~g}$ of water.

As the temperature change and airflow in the temperature measurement place can affect the volume of water, the experiment was conducted in a place where there was no temperature change and no airflow. The room temperature was kept constant $\left(25^{\circ} \mathrm{C}\right)$ using room temperature control equipment. The collection of water in the line of the urine bag can be a factor that reduces the volume; it was then assumed to have no effect on the volume during the continuous measurement. The actual amount injected (30 g) into the urine bag was measured 10 times to ensure the traceability of the urine bag (type A) in Table 1 . The average syringe weight to inject $30 \mathrm{~mL}$ was $30.06936 \pm 0.09796$. To confirm the error by repeated measurement, the same person (Table 2) measured $30 \mathrm{mg}$ of water 10 times.

\section{(2) Urine bag}

The urine bag does not have a calibration certificate.

Table 1. Measurement of the actual dose $(30 \mathrm{~g})$ repeatedly using urine bag $\mathrm{A}$

\begin{tabular}{lcccccccccc}
\hline & 1 & 2 & 3 & 4 & 5 & 6 & 7 & 8 & 9 & 10 \\
\hline Syringe (g) & 27.8709 & 28.1685 & 27.9401 & 28.1638 & 28.1638 & 28.0728 & 27.9552 & 28.0694 & 27.8707 & 27.9395 \\
Syringe with water $(\mathrm{g})$ & 57.9188 & 58.1945 & 57.9607 & 58.1794 & 58.3128 & 58.1031 & 58.0849 & 58.0547 & 58.1716 & 57.9278 \\
Water (g) & 30.0479 & 30.026 & 30.0206 & 30.0156 & 30.149 & 30.0303 & 30.1297 & 29.9853 & 30.3009 & 29.9883 \\
Measurement $(\mathrm{mL})$ & 32 & 31 & 31 & 30 & 30 & 31 & 31 & 31 & 31 & 31 \\
\hline
\end{tabular}

Table 2. Degree of distortion caused by angulation when measuring the volume with urine bag $A$

\begin{tabular}{|c|c|c|c|c|c|c|c|c|c|c|}
\hline & \multicolumn{10}{|c|}{ Water (g) } \\
\hline & 30.0479 & 30.026 & 30.0206 & 30.0156 & 30.149 & 30.0303 & 30.1297 & 29.9853 & 30.3009 & 29.9883 \\
\hline 1 & 31 & 30 & 30 & 29 & 29 & 30 & 30 & 30 & 30 & 30 \\
\hline 2 & 32 & 31 & 31 & 30 & 30 & 31 & 31 & 31 & 31 & 31 \\
\hline 3 & 32 & 31 & 31 & 30 & 31 & 32 & 31 & 32 & 31 & 32 \\
\hline 4 & 31 & 30 & 30 & 29 & 29 & 30 & 30 & 30 & 30 & 30 \\
\hline 5 & 32 & 31 & 31 & 30 & 30 & 31 & 31 & 31 & 31 & 31 \\
\hline 6 & 32 & 31 & 31 & 30 & 31 & 32 & 31 & 32 & 31 & 32 \\
\hline 7 & 31 & 30 & 30 & 29 & 29 & 29 & 30 & 30 & 30 & 30 \\
\hline 8 & 32 & 31 & 31 & 30 & 30 & 32 & 31 & 32 & 31 & 32 \\
\hline 9 & 32 & 31 & 31 & 30 & 31 & 31 & 31 & 31 & 31 & 31 \\
\hline 10 & 31 & 30 & 30 & 29 & 30 & 31 & 30 & 31 & 30 & 31 \\
\hline
\end{tabular}


Hyo Jung Son, et al: Volume uncertainty of urine bag

Table 3. Summary table of the uncertainty: urine bag A

\begin{tabular}{|c|c|c|c|c|c|}
\hline Uncertainty factory & Standard uncertainty & Type & $\begin{array}{l}\text { Sensitivity } \\
\text { coefficient }\end{array}$ & $\begin{array}{l}\text { Probability } \\
\text { distribution }\end{array}$ & $\begin{array}{c}\text { Degrees of } \\
\text { freedom }\end{array}$ \\
\hline Calibration uncertainty of electronic scale (repeated measurement) & $4.33232 \mathrm{E}-05$ & Type A & 1 & $\mathrm{t}$ & 9 \\
\hline Calibration uncertainty of electronic scale (test certificate) & 0.00015 & Type B & 1 & $\mathrm{t}$ & 9 \\
\hline Uncertainty of $30 \mathrm{~mL}$ & 0.030977672 & Type B & 1 & Normal & 9 \\
\hline Resolution of electronic scale (m) & $2.88675 \mathrm{E}-05$ & Type B & 1 & Rectangle & $\infty$ \\
\hline Uncertainty from measurement angle & 1.154700538 & Type B & 1 & Rectangle & $\infty$ \\
\hline Resolution of urine bag (m) & 0.288675135 & Type B & 1 & Rectangle & $\infty$ \\
\hline Combined standard uncertainty & 1.190641133 & & 1 & & $3.57 E+16$ \\
\hline Expanded uncertainty & 2.381282266 & & & & \\
\hline
\end{tabular}

\section{2) Type B standard uncertainty caused by angulation}

When measuring the liquid, the eye should be level with the liquid surface when reading the scale. Despite this, when using the usual method for the urine measurement, the measurement can differ according to a range of factors, such as the posture of the measurer and the distance. The maximum angle difference was estimated to be up to approximately $90^{\circ}$. The degree of distortion of the urine bag measurement caused by this angulation was measured to be up to $2 \mathrm{~mL}$. Theoretically, the probability of angulation is assumed to be constant and irrelevant to the angle. The data were assumed to have a rectangular probability distribution, and the type B uncertainty was calculated as follows:

$$
U_{B}=\frac{2}{\sqrt{3}}=1.154700538 \mathrm{~mL} .
$$

3) Type B standard uncertainty from a resolution of the

\section{urine bag}

The type B standard uncertainty from a resolution of the urine bag was assumed to follow a rectangular distribution, whose maximum value was $1 / 2$ of the minimum scale.

$$
U_{B}=\frac{0.5}{\sqrt{3}}=0.288675135 \mathrm{~mL} .
$$

\section{4) Evaluation of combined standard uncertainty of electronic scale and urine bag}

The combined uncertainty was calculated by combining the error from repeated measurements that takes part in the uncertainty of the volume measurement, resolution, and error of ruler scale with the uncertainty factor obtained above.

\section{5) Calculation of expanded uncertainty}

The expanded uncertainty can be found by calculating the effective degree of freedom based on the Welch-Satterthwaite equation [4] and multiplying it by the coverage factor, $\mathrm{k}=2$ (Table 3).

\section{6) Method of application to clinical judgment}

When injecting $30.1 \mathrm{~mL}$ of water on average into the urine bag. The measured values were distributed within $\pm 2.4 \mathrm{~mL}$ (7.0\%) with a probability of $95 \%$. Therefore, if the hypovolemic treatment is planned when the urine volume is $0.5 \mathrm{mg} / \mathrm{kg}$ or below in a $60-\mathrm{kg}$ patient, it is possible that the range of $30 \mathrm{~mL}$ to $32.4 \mathrm{~mL}$ may be abnormal, even if the urine volume of the patient is in the normal range. If the urine volume lies within this range, oliguria should be suspected clinically, considering that close observation and active treatment is required.

\section{Urine bag $B$}

1) Evaluation of the standard uncertainty of mess cylinder and urine bag

\section{(1) Mess cylinder}

The calibration uncertainty was obtained from a Calibration Certificate (type A standard uncertainty) of the mess cylinder. A $30 \mathrm{~g}$ mass of water was measured 10 times with a measuring cylinder (type A) to ensure the accuracy of the measuring cylinder. The measurement result was less than 0.05 of the actual value, which was regarded as a systematic error and was corrected to -0.05 .

The type B standard uncertainty from a resolution of the mess cylinder was assumed to follow a rectangular distribution, whose maximum value is $1 / 2$ of the minimum scale. 
The error of the mess cylinder was assumed to follow a rectangular distribution based on the calibration certificate.

\section{(2) Urine bag}

The urine bag does not have a calibration certificate. The mess cylinder was used to measure $30 \mathrm{~mL}$ and inject it into the urine bag for the volume measurement. The measurement result was observed to be approximately $0.5 \mathrm{~mL}$ lower than the actual value. This was regarded as a systematic error of $+0.5 \mathrm{~mL}$ because it can arouse an uncalibrated error. The mess cylinder was used to measure $300 \mathrm{~mL}$ and inject it into the urine bag for the volume measurement. The measurement result was approximately $59 \mathrm{~mL}$ lower than the actual value. This was regarded as a systematic error of $+59 \mathrm{~mL}$ because it can arouse an uncalibrated error.

As a temperature change and air flow in the temperature measurement place can affect the volume of water, the experiment was carried out by selecting a place with a constant temperature $\left(25^{\circ} \mathrm{C}\right)$ and air flow using an indoor temperature regulator.

The accumulation of water in the line of the urine bag can be a factor that reduces the volume; it is assumed to have no effect on the volume during the continuous measurement.

The volume of the urine bag can differ according to the location of the fastener. Accordingly, the maximum difference in the urine volume measurement of the urine bag caused by the fastener was up to approximately $2 \mathrm{~mL}$. Theoretically, the probability of distortion caused by the fasteners was assumed to be constant and irrelevant to the degree of the fastener. The data were assumed to have a rectangular probability distribution, and type B uncertainty can be calculated using Equation 2.

\section{2) Type B standard uncertainty caused by angulation}

\section{(1) $30 \mathrm{~mL}$ injection}

The maximum distortion of the urine volume measurement on the urine bag caused by such angulation was up to approximately $2 \mathrm{~mL}$. Theoretically, the probability of angulation is assumed to be constant and irrelevant of the angle. This was assumed to have a rectangular probability distribution, and the type B uncertainty can be calculated using Equation 2
(2) $300 \mathrm{~mL}$ injection

The maximum distortion of the urine volume measurement on the urine bag caused by such angulation was up to approximately $20 \mathrm{~mL}$. Theoretically, the probability of angulation was assumed to be constant and irrelevant of the degree of the angle. The data were assumed to have a rectangular probability distribution, and the type B uncertainty can be calculated as follows:

$$
U_{B}=\frac{20}{\sqrt{3}}=11.54700538 \mathrm{~mL} .
$$

3) Type B standard uncertainty from resolution of the urine bag

\section{(1) $30 \mathrm{~mL}$ injection}

The type B standard uncertainty from the resolution of the urine bag was assumed to follow a rectangular distribution, whose maximum value was $1 / 2$ of the minimum scale:

$$
U_{B}=\frac{5}{\sqrt{3}}=2.88675135 \mathrm{~mL}
$$

\section{(2) $300 \mathrm{~mL}$ injection}

The type B standard uncertainty from a resolution of the urine bag was assumed to follow a rectangular distribution, whose maximum value was $1 / 2$ of the minimum scale:

$$
U_{B}=\frac{50}{\sqrt{3}}=28.8675135 \mathrm{~mL} .
$$

4) Evaluation of the combined standard uncertainty of the mess cylinder and urine bag

The combined uncertainty was calculated by combining the error from the repeated measurement that takes part in the uncertainty of the volume measurement, resolution, and error of the ruler scale with the uncertainty factor obtained above.

\section{5) Calculation of expanded uncertainty}

The expanded uncertainty can be found by calculating the effective degree of freedom based on the Welch-Satterthwaite equation and multiplying it by the coverage factor, $\mathrm{k}=2$ (Tables 4 and 5). 
Hyo Jung Son, et al: Volume uncertainty of urine bag

Table 4. Summary of the uncertainty: $30 \mathrm{~mL}$ with urine bag $B$

\begin{tabular}{|c|c|c|c|c|c|}
\hline Uncertainty factory & $\begin{array}{c}\text { Standard } \\
\text { uncertainty }\end{array}$ & Type & $\begin{array}{l}\text { Sensitivity } \\
\text { coefficient }\end{array}$ & $\begin{array}{l}\text { Probability } \\
\text { distribution }\end{array}$ & $\begin{array}{l}\text { Degrees of } \\
\text { freedom }\end{array}$ \\
\hline Calibration uncertainty of electronic scale (repeated measurement) & 0.050596 & Type A & 1 & $\mathrm{t}$ & 9 \\
\hline Calibration uncertainty of electronic scale (test certificate) & 0.725 & Type B & 1 & $\mathrm{t}$ & 9 \\
\hline Uncertainty of $30 \mathrm{~mL}$ & 0.341526 & Type B & 1 & Normal & 9 \\
\hline Resolution of electronic scale (m) & 2.886751 & Type B & 1 & Rectangle & $\infty$ \\
\hline Uncertainty from location of the fastener & 1.154701 & Type B & 1 & Rectangle & $\infty$ \\
\hline Uncertainty from measurement angle & 1.154701 & & & & \\
\hline Resolution of urine bag (m) & 0.288675 & Type B & 1 & Rectangle & $\infty$ \\
\hline Combined standard uncertainty & 3.224101 & & 1 & & 3519.856 \\
\hline Expanded uncertainty & 6.448201 & & & & \\
\hline
\end{tabular}

Table 5. Summary of the uncertainty: $300 \mathrm{~mL}$ with urine bag B

\begin{tabular}{|c|c|c|c|c|c|}
\hline Uncertainty factory & $\begin{array}{c}\text { Standard } \\
\text { uncertainty }\end{array}$ & Type & $\begin{array}{l}\text { Sensitivity } \\
\text { coefficient }\end{array}$ & $\begin{array}{l}\text { Probability } \\
\text { distribution }\end{array}$ & $\begin{array}{c}\text { Degrees of } \\
\text { freedom }\end{array}$ \\
\hline Calibration uncertainty of electronic scale (repeated measurement) & 0.050596 & Type A & 1 & $\mathrm{t}$ & 9 \\
\hline Calibration uncertainty of electronic scale (test certificate) & 0.725 & Type B & 1 & t & 9 \\
\hline Uncertainty of $30 \mathrm{~mL}$ & 0.341526 & Type B & 1 & Normal & 9 \\
\hline Resolution of electronic scale $(\mathrm{m})$ & 2.886751 & Type B & 1 & Rectangle & $\infty$ \\
\hline Uncertainty from location of the fastener & 1.154701 & Type B & 1 & Rectangle & $\infty$ \\
\hline Uncertainty from measurement angle & 1.154701 & & & & \\
\hline Resolution of urine bag (m) & 0.288675 & Type B & 1 & Rectangle & $\infty$ \\
\hline Combined standard uncertainty & 29.07161 & & 1 & & 23268418 \\
\hline Expanded uncertainty & 58.14322 & & & & \\
\hline
\end{tabular}

\section{6) Method of application to clinical judgement}

\section{(1) $30 \mathrm{~mL}$ injection}

When $30 \mathrm{~mL}$ of water is injected into the urine bag, it is distributed within $\pm 6.4 \mathrm{~mL}$ (21.3\%) of the measured value with a probability of $95 \%$. Therefore, if a hypovolemic treatment is planned when the urine volume is $0.5 \mathrm{mg} / \mathrm{kg}$ or below in a $60 \mathrm{~kg}$ patient, a range of $30 \mathrm{~mL}$ to $36.4 \mathrm{~mL}$ may be abnormal, even if the urine volume of the patient is within the normal range. Therefore, the patient may not need to be careful when using this urine bag.

\section{(2) $300 \mathrm{~mL}$ injection}

When $300 \mathrm{~mL}$ of water is injected into the urine bag, it is distributed within $\pm 58.1 \mathrm{~mL}(19.4 \%)$ of the measured value with a probability of $95 \%$. Therefore, if some treatment is planned when the urine volume is $300 \mathrm{~mL}$ or below in a patient, it is possible that a range of 300 to $358.1 \mathrm{~mL}$ may be abnormal, even if the urine volume of the patient is in the normal range. Therefore, it may be inappropriate for the patient to be careful when using this urine bag.

\section{DISCUSSION}

Measurements of the urine volume are very helpful for diagnosing urinary diseases, including the kidney. In particular, measurements of the hourly urine volume during and after surgery are a classical indicator of acute kidney injury. In the department of anesthesiology and pain medicine, the hourly urine volume is checked as a means to monitor the patient's status during surgery. In surgery that involves a large volume of blood or water loss, it is important to measure the hourly urine volume to predict the intravascular volume.

Although an appropriate urine excretion volume does not ensure renal function, the recommended urine volume is $0.5 \mathrm{~mL} / \mathrm{kg} / \mathrm{h}$ or above. In addition, according to the Kidney Disease Improving Global Outcomes Clinical Practice Guidelines announced in 2012 [5], acute kidney injury is defined as a case, in which urine volume is kept below 0.5 $\mathrm{mL} / \mathrm{kg} / \mathrm{h}$ for at least 6 hours. The guideline suggests medical practice recommendations based on the severity level. An observation of oliguria may indicate a lack of circulating 
blood volume, antidiuretic effect of the anesthetic agent [ $]$, stress from surgery, and imminence of acute renal failure [7]. In addition, when managing sap during surgery, the recently collected urine volume can be considered when determining the future sap volume. Medicines, such as diuretics, are sometimes used to increase the urine volume [8]. Intravascular volume management during surgery also affects the incidence of acute kidney injury and intensive care during the postoperative periods [0].

The term 'uncertainty' generally indicates the uncertainty of measurement of the measured data. This means the extent of inaccuracy of the measured data as there can be a difference in the measured value, even when the same tester measures with an identical instrument under the same conditions. The measurement uncertainty is a parameter characterizing the dispersion of values attributed to the repeated measured quantity, such as the standard deviation, width of the confidence interval, and others. This index presents the accuracy of the measured data under controlled conditions and is used widely as a value that represents the reliability of the measured data [10]. In 1993, the ISO published 'Guide to the Expression of Uncertainty in Measurement,' which can be applied to all measurement fields, with cooperation with other international organizations [11]. According to this guideline, the uncertainty in measurement is defined as the estimated value that expresses the range of true values, and is classified as types A and B. Type A uncertainty is defined as the uncertainty that can be estimated from statistical data, and type B uncertainty is presented as the uncertainty that can be estimated with methods other than statistics. In addition, the ISO published 'Guidelines on estimation of Uncertainty of results' and defined combined standard uncertainty and expanded uncertainty [12]. The combined standard uncertainty is a calculation of each uncertainty from the type A and B uncertainty from the square root of the increased dispersion and covariance along the effect of a change in the input value on the measured result. In addition, the expanded uncertainty is calculated with a multiplication of combined standard uncertainty by a factor to assess the range where measured value is expected to be.

This study showed that it is possible to confirm the uncertainty of the problems caused by the randomness in the measurement of the actual urine output. Based on this study, it is possible to evaluate the accurate urine bag performance according to the actual urine volume. This can help improve the national standards and permit regulations based on articles monitoring the renal function in ordinary patients through accurate checking of the urine output, and reinforce the functions of urine bags as a patient monitor that requires precision.

\section{CONFLICT OF INTEREST}

No potential conflict of interest relevant to this article was reported..

\section{REFERENCES}

1. ISO. ISO 8669-2: Urine collection bags-part 2: Requirements and test methods. Geneva: ISO; 1996.

2. ISO/IEC Guide 98-3:2008. Uncertainty of measurement-part 3: Guide to the expression of uncertainty in measurement (GUM:1995). 4.2 Type A evaluation of standard uncertainty.

3. ISO/IEC Guide 98-3:2008. Uncertainty of measurement-part 3: Guide to the expression of uncertainty in measurement (GUM:1995). 4.2 Type B evaluation of standard uncertainty.

4. Willink R. A generalization of the Welch-Satterthwaite formula for use with correlated uncertainty components. Metrologia 2007; 44:340-9.

5. John A, Norbert L, Peter A, Alison MM, Rashad SB, Ravindra L, et al. KDIGO clinical practice guideline for acute kidney injury. Kidney Int Suppl 2012;2:1-138.

6. Burchardi H, Kaczmarczyk G. The effect of anaesthesia on renal function. Eur J Anaesthesiol 1994;11:163-8.

7. Goren O, Matot I. Perioperative acute kidney injury. Br J Anaesth 2015;115 Suppl 2:ii3-14.

8. Ho KM, Power BM. Benefits and risks of furosemide in acute kidney injury. Anaesthesia 2010;65:283-93.

9. Moore EM, Bellomo R, Nichol AD. The meaning of acute kidney injury and its relevance to intensive care and anaesthesia. Anaesth Intensive Care 2012;40:929-48.

10. ISO/IEC Guide 98-3:2008. Uncertainty of measurement-part 3: Guide to the expression of uncertainty in measurement (GUM:1995).

11. CODEX. CAC/GL 54-2004 guidelines on measurement uncertainty.

12. CODEX. CAC/GL 59-2006 guidelines on estimation of uncertainty of results. 